\title{
International Journal of Applied Geospatial Research
}

\section{April-June 2011, Vol. 2, No. 2}

\section{Table of Contents}

\section{Editorial Preface}

i Recent Highlights from the Applied Geography Specialty Group

Donald P. Albert, Sam Houston State University, USA

\section{Guest Editorial Preface}

iii Association of American Geographers Applied Geography Specialty Group 2009/2010: A Year in Review

Nairne Cameron, Algoma University, Canada

\section{Research Articles}

1 Communities, Cartography and GIS: Enhancing Undergraduate Geographic Education with Service Learning

Timothy L. Hawthorne, Columbus State University, USA

17 Colorado 14ers, Pixel by Pixel

Brandon J. Vogt, University of Colorado at Colorado Springs, USA

\section{Case Study}

33 Leveraging the Science of Geographic Information Systems

Rick Bunch, University of North Carolina at Greensboro, USA

Anna Tapp, University of North Carolina at Greensboro, USA

Prasad Pathak, University of North Carolina at Greensboro, USA

\section{Research Commentary}

39 Increasing the Flexibility of Legacy Systems

William L. Garrison, University of California at Berkeley, USA

Barry Wellar, University of Ottawa and Wellar Consulting Inc., Canada

Ross MacKinnon, University of Connecticut, USA

William R. Black, Indiana University, USA

Arthur Getis, San Diego State University, USA 


\title{
Case Study \\ Leveraging the Science of Geographic Information Systems
}

\author{
Rick Bunch, University of North Carolina at Greensboro, USA \\ Anna Tapp, University of North Carolina at Greensboro, USA \\ Prasad Pathak, University of North Carolina at Greensboro, USA
}

\begin{abstract}
The Center for Geographic Information Science (CGISc) at the University of North Carolina Greensboro (UNCG) was established in the Summer of 2006. CGISc is an educational research entity that relies on the use of GIS and the science of geographic information to conduct research on human and natural phenomena distributed on the Earth's surface. CGISc welcomes interdisciplinary collaboration, and emphasizes the development of public-private sector partnerships. CGISc also places a high priority on research that involves students. This paper first provides an overview of the CGISc. This section is followed by a discussion on the fundamental approach to conducting geographic research using GIS. The paper concludes with several significant projects and a discussion on future directions.
\end{abstract}

Keywords: Geographic Analysis, Geographic Information Science, Geographic Information Systems, Geographic Research, Human and Natural Phenomena

\section{OVERVIEW}

The Center for Geographic Information Science (CGISc) is housed in the Department of Geography at the University of North Carolina at Greensboro(UNCG). CGISc is an educational research entity that uses theories, concepts, and applications to solve, analyze, and model geographic aspects of human and environmental phenomena. CGISc seeks interdisciplinary partnerships, with a focus on providing robust geographic analyses to investigate complex problems. CGISc places an emphasis on fostering public-private sector partnerships and

DOI: 10.4018/jagr.2011040103 developing transformative geospatial technology and applications. The contributions of both graduate and undergraduate students are integral to the Center's activities.

Following national trends in the United States, the Department of Geography at UNCG has experienced substantial growth over the past 15 years. During this time period, the number of tenure-track faculty has nearly doubled to support the incremental additions of the master's and doctoral programs. The department now has approximately 85 undergraduate majors, 45 master's students, and 25 doctoral students. Departmental growth and an increase in geographic information science research activity justified the creation of CGISc. In the summer 
of 2006 the Center was proposed by Dr. Rick Bunch and approved by the university.

Initial university support for CGISc included a small amount of physical workspace, a modest operating budget, and personnel funding to hire Anna Tapp as the full-time Associate Director. CGISc also received funding to purchase computers and geospatial software. Initially, several ongoing externally funded projects were strategically integrated as part of CGISc activities. These activities primed a research agenda and provided additional monetary support.

Over the past four years, CGISc has experienced significant growth in nearly all aspects. The Center has funded numerous graduate and undergraduate student assistantships, many of which have led to culminating dissertation and thesis topics. Additionally, CGISc has more than doubled its operating budget, increased its physical workspace by fifteen-fold, and significantly increased its access to geospatial software, computers and hardware (Figure 1). CGISc has also added 3 full-time personnel - a post doctoral research associate and two specialists in Geographic Information Systems (GIS).

\section{APPROACH TO RESEARCH}

The value of GIS varies according to the perception of the user. Some people might view the technology as a way to automate the production of maps. Others might see the technology as a tool for storing, maintaining, updating, and querying large geospatial databases (e.g., utilities, land parcels). Yet other people may see it as a way to analyze geographic relationships among phenomena (e.g., cancer prevalence in relation to the locations of health care facilities). How individuals or organizations use GIS has led to the identification of two paradigms - the spatial information paradigm and the spatial analysis paradigm (Goodchild, 1991). The spatial information paradigm emphasizes the database and query aspects of GIS, while the spatial analysis paradigm focuses on modeling.
These two paradigms, in part, provided the foundation for delineating the emergence of Geographic Information Science (GIScience) (Goodchild, 1991, 1992).

The spatial information and spatial analysis paradigms are useful for understanding different arguments about the value of GIS in academics, particularly within the context of geographic research. Kitchin and Sidaway (2006) raised questions about trends toward promoting GIS as a way to enhance Geography as a discipline. As part of a much broader argument, they pointed out that the promotion of GIS provides shortterm visibility, but over the long-term it can reduce geographers to technicians. This argument embodies the spatial information paradigm where individuals are trained to build, maintain, and query geographic databases. Others, however, have argued that research leveraging GIS and the science of geographic information can enable collaborative environments and promote participation of critical geographic inquiry (Klinkenburg, 2007; Schuurman, 2009). This argument clearly embraces the spatial analysis paradigm where the science behind GIS is used to carry out research.

CGISc's approach is to place value on both the spatial information and the spatial analysis paradigms. On one level, students who work with CGISc are trained to handle and process geographic data and information. This is the first step in a long-term learning process, but it is only the beginning. Students are further exposed to various geographic methods and scientific approaches through coursework and hands-on research experience. This incremental learning process helps students develop the skills needed to conceptualize, represent, analyze, and express solutions to geographic problems through a GIS. This approach directly supports the research philosophy of CGISc, which considers GIScience a field of inquiry providing the scientific context for conducting research related to GIS. CGISc consequently leverages both GIS and the science of problem solving with the purpose of analyzing geographic problems and discovering new knowledge. 
Figure 1. The meeting room

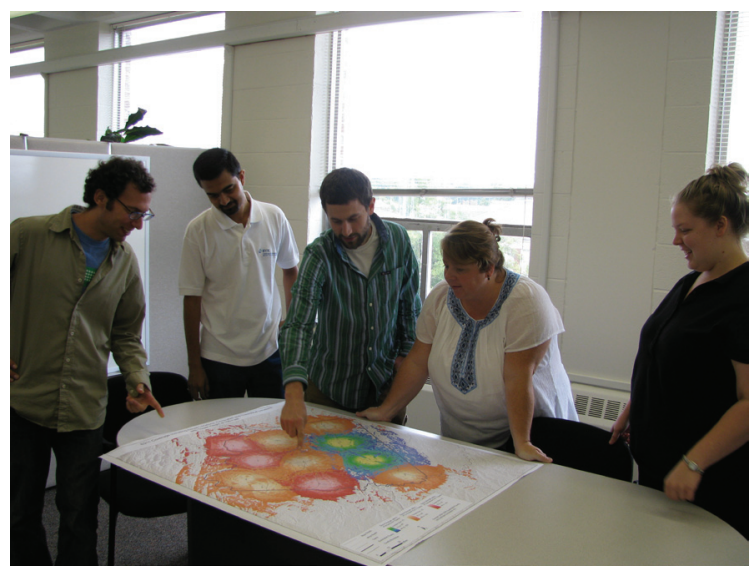

\section{PROJECTS}

Over the past 4 years, CGISc has been involved in a number of exciting research projects. Internally, CGISc integrated utilities data into a GIS for Facilities Management, provided crime mapping and analyses for the Center for Youth, Family and Community Partnerships, analyzed the accessibility of grocery stores to local ethnic communities, and provided a wide range of other GIS services for various offices, faculty, and students.

Externally, CGISc has been involved in varied geographic research. Radio wave propagation modeling using GIS has dominated the research agenda; however, the Center has completed a number of other significant projects. These include bioterrorism preparation and response, retail and commercial property site selection, banking and customer behavior analysis, health care marketing and analysis, school bus routing, and the availability of gynecologic oncologists in relation to the locations of ovarian cancer patients. Each of these ventures has relied on the analysis of geographic space and the use of GIS as central themes.

\section{Radio Wave Propagation Modeling}

Wagen and Rizk (2003) published an article titled "Radiowave propagation, building data- bases, and GIS: Anything in common? A radio engineer's viewpoint." In this article, they addressed the problems associated with widely used propagation software, and expressed the need for more accurate and detailed models of the physical and built environment. They argued that GIS was ideally suited for this task, and that it can provide the necessary data, functionality and architecture for improving the modeling process (Figure 2).

CGISc uses geographic concepts, methods and GIS to meet the needs of several important components in the propagation modeling process (Tapp \& Bunch, 2008). The major components in the modeling processes are: 1) Antenna specifications and locations, 2) An equation to capture the behavior of radio waves, 3)An elevation model representing "bare earth," 4) Methods and models for capturing the impacts of clutter such as natural (vegetation) and manmade features (buildings), and 5) Assessment and validation.

Antenna specifications and their locations are typically collected from network providers and stored in a GIS to prime the modeling process. Computer-generated mapping of radio wave propagation through the atmosphere is accomplished through a combination of deterministic and empirical models. The empirical models are based on thousands of signal strength measurements taken by researchers over the 
Figure 2. The radio wave propagation modeling process

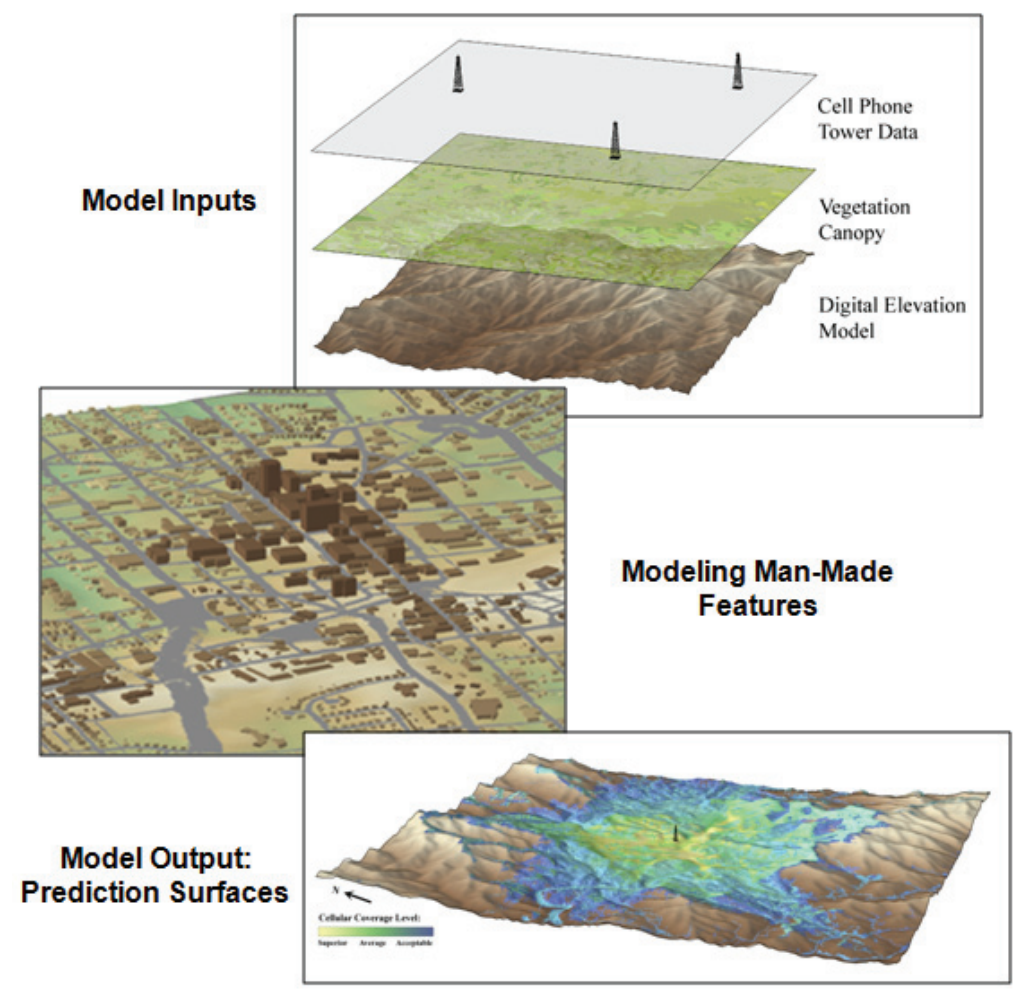

years. The deterministic models attempt to pinpoint the specific impact of ground cover on signal strength. The intent is to model approximate seasonal coverage changes. In both types of models, the radio wave loss is based on factors such as transmitter-receiver distance, transmitter power, and frequency. The final product is refined to incorporate the impact of topography. The process of deriving or selecting equations is based on the assumptions of the equations as well as intimate knowledge of the geography of the area being predicted. In many cases, multiple equations are used for each antenna to predict network coverage. The flexibility of GIS allows us to immediately incorporate new equations derived from the Center's research or research conducted by engineers.

Acquiring data is a key element in deriving elevation models for propagation predictions. Whenever possible, we create our own elevation models by processing all returns Light Detection and Ranging (LIDAR) remote sensor data. Because these data consist of millions of points, we can generate customized models with much higher spatial resolution than traditional Digital Elevation Models (DEMs). Representing other natural and man-made features in propagation models is another important component. This is an area where GIS thrives and where CGISc creates custom models unique to specific regions. The Center derives its own models of the environment using unique datasets and methods developed and tested through previous research and field work.

The assessment and validation of the model is accomplished through signal strength data collected from drive tests and field sampling. A spatial sampling procedure is used to select testing sites. Data derived from the spatial sampling procedure is subjected to statistical 
analysis both to calibrate and to determine the overall accuracy of the modeling process.

CGISc has worked on many projects of various size and scope with a planning and engineering firm that specializes in master plans for mobile wireless communications. This partnership has continued for over 6 years, predating the inception of the Center. CGISc has been tasked with supporting telecommunications master plans by providing reliable coverage prediction maps of existing infrastructure. CGISc is also charged with generating computer simulated "what if" scenarios to identify the impacts of adding, changing, or removing features in the mobile wireless network. Over time, the models have been greatly improved through cycles of experimentation and the inclusion of more accurate representations of terrain and vegetation. The research has occurred in various locations throughout the U.S. Examples include urban, suburban and rural areas of Alaska, Florida, North Carolina, Virginia, and Washington.

CGISc has also collaborated with a major petroleum and natural gas company. This work involved the implementation of a wireless communication network planning and optimization system using GIS. The company's fixed wireless communication network monitors parameters such as flow, pressure, and temperature for the pipeline infrastructure. The system used over 5,000 interconnected transmitters dispersed throughout three states to feed data to a central monitoring system. Researchers at CGISc used a data model that incorporated the company's network, and leveraged topology to capture connectivity. CGISc also created methods for developing coverage prediction models and provided a 4-day workshop to train company employees to use the system.

Recently, CGISc has partnered with the e-NCAuthority, which received federal support from the U.S. Department of Commerce under the State Broadband Data and Development Grant Program. The e-NC Authority was created by the North Carolina General Assembly to manage, oversee, and monitor efforts to provide rural counties and distressed urban areas with high-speed broadband Internet in
North Carolina. The role of CGISc is to create statewide coverage prediction surfaces for wireless broadband networks. Custom radio wave propagation models for existing wireless broadband networks are currently being created to help identify unserved and underserved regions throughout the state. The model uses a unique blend of high spatial resolution datasets and formulas to capture the effects of natural terrain, vegetation interference, and the behavior of radio waves in space.

Moving beyond coverage prediction and onto issues related to wireless network capacity, CGISc has investigated how well providers are serving communities, particularly in rural areas. This line of inquiry led to the creation of new interpolation methods to increase the spatial resolution of U.S. Census data (Tapp, 2010). Using these new methods, CGISc can overlay antenna coverage areas over realistic population surfaces. The researcher can determine if the antenna coverage is geographically serving communities, and if the infrastructure is adequate for the population density of the area. Using the same logic, unserved populations can be readily identified, and optimal locations of future infrastructure determined.

\section{THE FUTURE}

CGISc will continue to focus on GIS and radio wave propagation modeling, leveraging the potential of GIS to improve the modeling process. Currently GIS is not well suited to deal with the spatiotemporal issues associated with incorporating vegetation changes that occur throughout different seasons. It is well known that the type and density of vegetation greatly influence radio wave attenuation. Signal strength prediction surfaces, for example, are very different in the summer than in the winter, especially in areas that experience distinct seasons. Capturing the spatiotemporal impacts of vegetation is computationally intense. CGISc is currently working on data collection methods and the use of neural network software to help address seasonal vegetation changes. CGISc is 
also exploring the use of graphics processing units and a GIS that supports parallel computing to help improve the modeling and computation of large datasets.

CGISc will stress collaboration with social scientists whose research could benefit from geographic analysis. As an example, a priority will be placed on interdisciplinary research that integrates CGISc's strengths in GIS and research in spatial cognition (Bunch, 2000; Bunch \& Lloyd, 2006; Lloyd \& Bunch, 2008). CGISc has initiated a project that uses GIS and cognitive mapping to examine crime locations and cognitive maps of law enforcement officers and community members. In general terms, the space produced by people's cognitive maps can be compared to geographic space as way to reveal patterns and bias in human behavior. Understanding these complex patterns could ultimately lead to creative solutions to societal problems.

The rapidly changing technology and new developments in geographic analysis place great importance on educating a new generation of students who can conceptualize and solve geographic problems in a meaningful way. In the future, CGISc will continue to focus on using science as a way to examine geographic information. CGISc will also strengthen existing partnerships, and develop new relationships. By exploring new and innovative ideas, CGISc will provide students with unique learning experiences and prepare them to meet future challenges.

\section{REFERENCES}

Bunch, R. (2000). GIS and the acquisition of spatial information: Differences among adults and young adolescents. Research in Geographic Education, 2, 65-95.
Bunch, R., \& Lloyd, R. (2006). The cognitive load of geographic information. The Professional Geographer, 58(2), 209-220. doi:10.1111/j.14679272.2006.00527.x

Goodchild, M. F. (1991). Towards a science of geographic information. In Cadoux-Hudson, J., \& Heywood, I. (Eds.), Geographic information 1991: The yearbook of the association for geographic information (Vol. 151, pp. 212-218). London, UK: Taylor \& Francis.

Goodchild, M. F. (1992). Geographical information science. International Journal of Geographical Information Systems, 6(1), 31-45. doi:10.1080/02693799208901893

Kitchin, R., \& Sidaway, J. D. (2006). Geography's strategies. The Professional Geographer, 58(4), 485-491. doi:10.1111/j.1467-9272.2006.00584.x

Klinkenburg, B. (2007). Geospatial technologies and geographies of hope and fear. Annals of the Association of American Geographers. Association of American Geographers, 97(2), 350-360. doi:10.1111/j.1467-8306.2007.00541.x

Lloyd, R., \& Bunch, R. (2008). Explaining mapreading performance efficiency: Gender, memory, and geographic information. Cartography and Geographic Information Science, 35, 171-202. doi: $10.1559 / 152304008784864677$

Schuurman, N. (2009). Critical GIScience in Canada in the new millennium. Canadian Geographer, 53(2), 139-144. doi:10.1111/j.1541-0064.2009.00250.x

Tapp, A. (2010). Areal interpolation and dasymetric mapping methods using local ancillary data sources. Cartography and Geographic Information Science, 37(3),215-228. doi:10.1559/152304010792194976

Tapp, A., \& Bunch, R. (2008). Mapping the invisible world: Modeling wireless communications with geographic information systems. American Congress on Surveying and Mapping, 232, 14-17.

Wagen, J.-F., \& Rizk, K. (2003). Radiowave propagation, building databases, and GIS: Anything in common? A radio engineer's viewpoint. Environment and Planning. B, Planning \& Design, 30(5), 767-787. doi:10.1068/b2958 